\title{
The Effect of Gas Nitriding on Wear of Drill Bits during Particle Board Drilling
}

\author{
Bolesław Porankiewicz*, Leszek Małdziński ${ }^{1}$, Grzegorz Wieloch ${ }^{2}$ \\ ${ }^{1}$ Poznań University of Technology, Poland \\ ${ }^{2}$ University of Life Science Poznań, Poland \\ *e-mail: poranek@amu.edu.pl
}

(Received: 10 February 2012; accepted: 5 June 2012; published online: 3 September 2012)

\begin{abstract}
In this paper multi-factor, non-linear, statistical dependencies between drill bit side edges recession $V B_{K F}$ $(\mathrm{mm})$ and drill bit diameter recession $\Delta D_{D}(\mathrm{~mm})$ upon cutting path $L_{C}(\mathrm{~m})$, and thickness $t_{N}(\mu \mathrm{m})$ of a nitrided coating layer after drilling coated particle board are determined. Significant influences of the cutting path $L_{C}$, and the thickness $t_{N}$ of the gas nitrided coating layer together with an interaction on the $V B_{K F}$ and the $\Delta D_{D}$ are evidenced. Dependency between hole edge swelling $S_{W}(\mathrm{~mm})$ and drill bit side edges recession $V B_{K F}$ is also evaluated.
\end{abstract}

Key words: spiral drill bit, side edges recession, drill bit diameter recession; hole edge swelling, boring; particle board, nitrided coating kayer

\section{INTRODUCTION}

Although a large number of methods for creating super hard, anti-wear layers, for example gas nitriding, Chemical Vapor Deposition (CVD), Physical Vapor Deposition (PVD), also called ion coating (Sokołowska et al. 2000; Chekour et al. 2003), and other methods with various modification have been known, extensive efforts are being continued to develop a method of coating capable of achieving a large increase in tool life at a relatively low cost, and avoiding disadvantages such as delamination, process temperature, size problems related to the working part and grip part dimensions, etc. Delamination has its source in insufficient attachment of the coating layer to the tool material body by a large difference between expansion coefficients and influence of thermal shock, as well as impact of corrosion effects during cutting (Sokołowska et al. 2000). Rather than super large hardness (hardness gradient), a good interface between the coating layer and tool bulk material provides large wearing resistance. The application of multiple coatings is recently considered the most promising research direction.

What is also worth noting is the important role of material machined properties such as the content and size of hard mineral contamination as well as low and high temperature tribochemical reactions of the tool material. The wearing resistance of the same coating may differ significantly for good (low mineral contaminated and low corrosive) and bad (highly corrosive and high mineral contaminated) material machined. From these reasons, there arises a strong postulate of complete evaluation of the properties of material machined, allowing for future comparison of the experiment results.

In the work of Szymański et al. 1980, it has been reported (on diagrams without the statistics worked out) a 2.4 times increase of the SW7M (high speed steel of $T$ grade), controlled gas nitrided drills after drilling a wide surface, of the polyvinyl chloride (PVC) coated, particle board. Although the friction coefficient of the nitrided layer is lower for wood in comparison to steel (Beer et al. 1998), in metal machining a much larger effect of tool life increase was observed by up to 10 times. The smaller effect of the particle board drilling tools' life has its source in a very small sharpness angle of drill side cutters necessary for high quality of holes edge formation. The drill side edges protect the holes edge against chipping, which is especially important for brittle melamine and veneer particle board coating. According to the research results, the main problem of formation of a good material machined edge is not its high hardness (hardness gradient) but the tear-off strength of the very thin outer layer (Porankiewicz 2003). In case of a coated particle board, insufficient tear-off strength of the skin may be caused by not having removed the porous and rough particle board skin during the calibration process or defects in coating and gluing. In case of thermoplastic particle board coatings, for example PVC, as well as for paper based coating and for fiber boards, the drills side edges also protect against 
swelling. It has to be mentioned that the cutting edge wear itself increases damages of a work piece edge after cutting of all kinds of material machined.

The present study attempts to evaluate statistical dependencies of the drill bit wear, defined by the drill bit side edge $V B_{K F}$ and the diameter $\Delta D_{D}$ recessions, upon the thickness of nitrided coating $t_{N}$ created with use of controlled gas nitriding, as well as dependency between the drill bit side edge wear $V B_{K F}$ and the hole swelling $S_{W}$ after drilling PVC coated particle board.

\section{EXPERIMENTAL}

The machining experiment analyzed in the present study was performed at the woodworking machinery laboratory, at Agriculture University of Poznań (Szymański 1977; Szymański et al. 1980). For machining tests a multispindle drilling machine DCWGW 19 (Fig. 1) by vertical position of working unit $\underline{1}$ was used. For fixing work piece $\underline{3}$ on machine working Table 4 two pneumatic cylinders $\underline{7}$ were used. Short, two edges spiral drill bits (Fig. 2) equipped in the centering spike $\underline{3}$ and two side edges $\underline{2}$ and the cylindrical grip $\underline{5}$ were tested. The following machining parameters typical for such machining operation were applied:

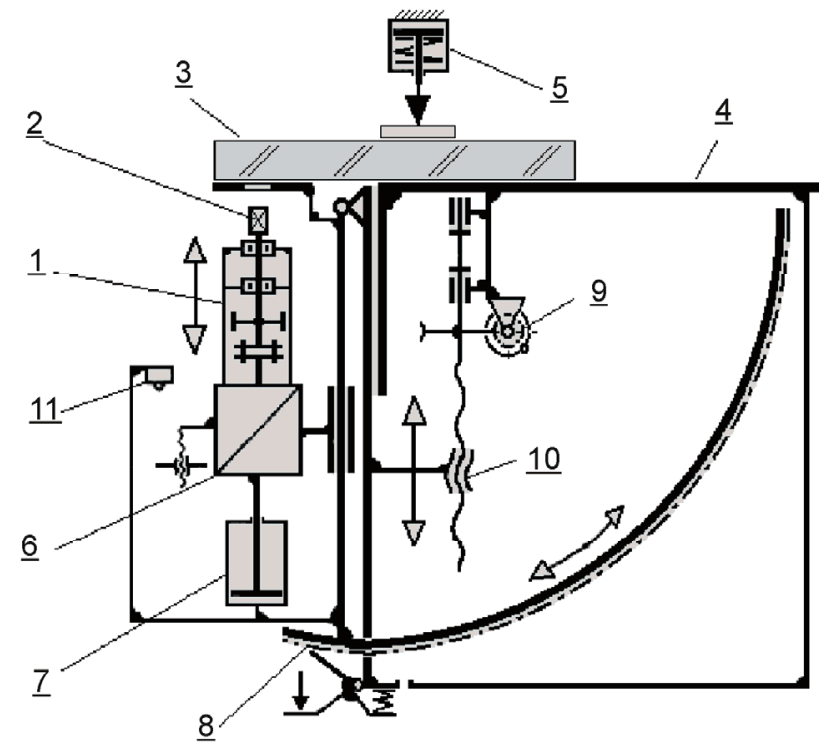

Fig. 1. Scheme of the multi-spindle drilling machine DCWGW 19; 1 - Working unit, 2 - Drill bit, 3 - Work piece, 4 - Working table, 5 - Air cylinders, 6 - Electrical motor, 7 - Working unit feed air cylinder, 8 - Latch mechanism, 9 - Snail gear box, 10 - Screw mechanism, 11 - End switch

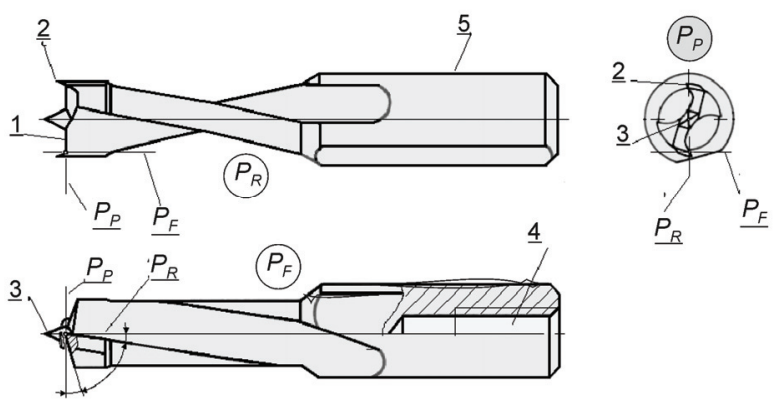

Fig. 2. Stereometrical parameters of the drill bit; 1 - Main (face) cutting edge, 2 - Side edge, 3 - Centering spike, 4 - Hole threaded for fixing screw, 5 - Cylindrical grip, $P_{F}-$ Working plain, $P_{R}$ - Tool reference plain, $P_{P}-$ Back plain

\section{Machining parameters}

- Spindle rotational speed $n=2880 \mathrm{~min}^{-1}$.

- Maximum cutting speed $v_{C}=1.13 \mathrm{~m} \cdot \mathrm{s}^{-1}$.

- Feed speed $v_{F}=0.84 \mathrm{~m} \cdot \mathrm{min}^{-1}$.

- Feed per revolution $f_{R}=0.6 \mathrm{~mm}$.

- Depth of an hole drilled $H_{0}=12 \mathrm{~mm}, S_{D}=0.2 \mathrm{~mm}$.

- The holes were drilled perpendicularly to the wide surface of particle board specimen.

Parameters of the spiral drill bit (Fig. 2)

- Maximum, main edge contour rake angle $\gamma_{F}=16.24^{\circ}$, $S_{D}=2.12^{\circ}$

- Maximum, main edge contour clearance angle $\alpha_{F}=20.28^{\circ}, S_{D}=2.47^{\circ}$.

- Main cutting edge inclination angle in base (frontal) plain $\psi_{R}=0^{\circ}$.

- Wedge angle of the side edge $\beta_{S E}=40.5^{\circ}, S_{D}=2.42^{\circ}$.

- Drill bit diameter $D_{D}=8 \mathrm{~mm}, S_{D}=0.09 \mathrm{~mm}$.

- Recession of the drill bit diameter $\Delta D_{D}<0.006 \ldots$ $0.224>\mathrm{mm}$.

- Drill bit working part side axial and tangential taper $0^{\circ}$.

- Stiffness of the drill bit mounted in a spindle $\varepsilon_{D}=$ $=190 \mathrm{~N} \cdot \mathrm{mm}^{-1}, S_{D}=38 \mathrm{~N} \cdot \mathrm{mm}^{-1}$.

- Number of cutting edges $z=2$.

- Material of the drill bit body was the high speed steel (HSS) type SW12C ( $T$ grade).

- Hardness of the drill bit material 64-66 HRC.

- Coefficient of heat transfer $\lambda=31.4 \mathrm{~W} \cdot \mathrm{m}^{-1} \mathrm{~K}^{-1}$.

- SW12C steel density $8200 \mathrm{~kg} \cdot \mathrm{m}^{-3}$.

- SW12C steel coefficient of linear expansion $13 \cdot 10^{-6} \mathrm{~K}^{-1}$.

- Dissociation level of ammonia $\left(\mathrm{NH}_{4}\right) 60 \%$, by temperature $520^{\circ} \mathrm{C}$.

- Time of controlled gas nitriding process $<0,50,80$, $110,140,165,170>\min$.

- Thickness of nitrided coating layer $t_{N}<0,35,50,60$, $70,75,78>\mu \mathrm{m}$. 
A scanning electron microscope (SEM) cross-section image of the nitrided layer was shown in Fig. 3. The hardness of the coating layer gradually decreased from $1050 \mathrm{HV}$ (70 HRC) down to the hardness of drill bit's bulk material.

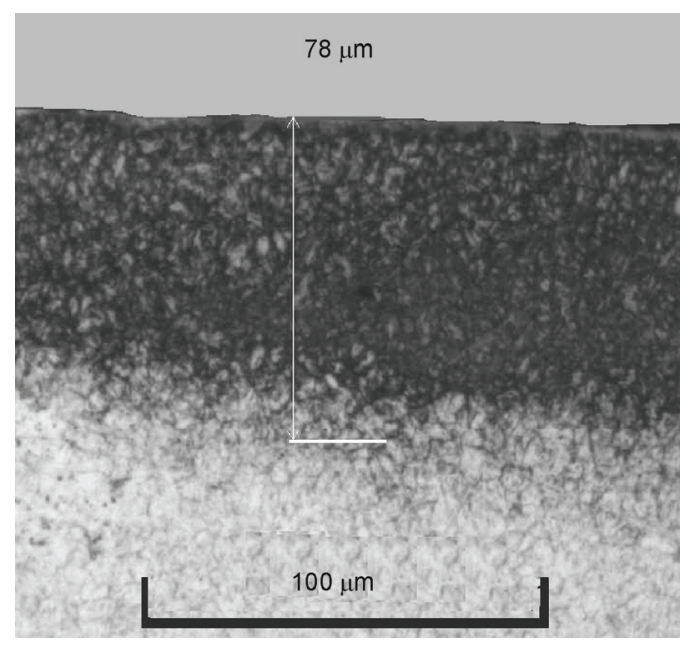

Fig. 3. SEM image of the thickest nitrided coating of the drill bit

Physical properties of urea-formaldehyde, PVC coated particle boards

- Density of particle board $658 \mathrm{~kg} \cdot \mathrm{m}^{-3}$.

- Density of PVC coating $1200 \mathrm{~kg} \cdot \mathrm{m}^{-3}$.

- Average density of PVC coated particle board $705 \mathrm{~kg} \cdot \mathrm{m}^{-3}$.

- Thickness of the coated particle board $16 \mathrm{~mm}$.

- Thickness of the PVC coating $0.2 \mathrm{~mm}$.

- Moisture content 3-3.5\%.

- Swelling of hole edge in PVC coated particle board after drilling $S_{W}<0.35 \ldots 0.121>\mathrm{mm}$, picked up from work of Szymański (1977).

The depended variable were:

- The drill bit side edge recession $V B_{S E}(\mathrm{~mm})$ measured in projection on a side working plane,

- The recession of the drill bit diameter $\Delta D_{D}(\mathrm{~mm})$,

- The swelling of hole edge $S_{W}(\mathrm{~mm})$ after drilling.

The drill bit side edge recession $V B_{S E}$ and the recession of the drill bit diameter $\Delta D_{D}$ were the physical tool life criterion. The hole edge swelling $S_{W}$ was the technological tool life criterion.

In the present study a quantifier describing high temperature tribochemical reactions (HTTR) between particle board tested and binder of tool material, according to the method described in work Porankiewicz (2003) was not evaluated.
The cutting path $L_{C}$ was evaluated from Eq. (1).

$$
\begin{aligned}
& L_{C}=I_{H} \cdot\left(H_{O}+H_{S E}-V B_{S E}\right) . \\
& \cdot f_{R}^{-1} \cdot\left[\left(\pi \cdot D_{D}\right)^{2}+f_{R}^{2}\right]^{-1 / 2} \cdot 0.001 \mathrm{~m} .
\end{aligned}
$$

In Eq. (1) the new term is:

$I_{H}$ - number of holes drilled.

The controlled gas nitriding process of high speed steel (HSS) type SW12C ( $T$ grade) was conducted in an electrical furnace with the application of the ZefoFlow method.

A statistical model of the relation $V B_{S E}=f\left(L_{C}, t_{N}\right)$ and $S_{W}=f\left(V B_{S E}\right)$ and $\Delta D_{D}=f\left(L_{C}, t_{N}\right)$ should fit the experimental matrix by the lowest summation of residuals square $S_{K}$, by the lowest $S_{D}$, and by the highest correlation coefficient $R$ between predicted and observed values. It is also very important to get the proper influence of variables analyzed, especially in the case of an incomplete experimental matrix. Using a simpler model usually results in decreasing approximation quality (larger $S_{K}$ and $S_{D}$, and lower $R$ ) and also may reverse the impact of lower importance variables. It also has to be pointed out that the statistical relationship is valid only for ranges of independent variables chosen in the experimental matrix. For some functions, points lying outside the analyzed range of independent variables, especially evaluated for an incomplete experimental matrix, are usually charged by a significant error. In the authors' opinion additional justification of a choice of a certain type of function makes sense when several experiments under the same machining conditions have already been done.

In the evaluation process of statistical dependencies $V B_{S E}=f\left(L_{C}, t_{N}\right)$ and $S_{W}=f\left(V B_{S E}\right)$ and $\Delta D_{D}=f\left(L_{C}, t_{N}\right)$ linear functions, second order multinomial formulas, as well as a power type and exponential functions, with and without interactions, were analyzed in preliminary calculations. The most adequate models, according to the assumptions made, appeared to be Eqs. (2), (3) and (4). It has to be pointed out that because of local maximum in relation $V B_{S E}=f\left(t_{N}\right)$ and $\Delta D_{D}=f\left(t_{N}\right)$ in range of $t_{N}<0,30>\mu \mathrm{m}$, during the evaluation process, several other solutions for dependencies $V B_{S E}=f\left(L_{C}, t_{N}\right)$ and $\Delta D_{D}=f\left(L_{C}, t_{N}\right)$, by lower $S_{K}$ were rejected. Estimators were evaluated from the complete experimental matrix containing 42 data points.

$$
\begin{aligned}
V B_{S E} & =a_{1} \cdot L_{C}^{a_{2}} \cdot\left(a_{3} \cdot t_{N}^{2}+a_{4} \cdot t_{N}+a_{5}\right)+a_{6} \quad(\mathrm{~mm}) \\
S_{W} & =c_{1} \cdot V B_{W}^{2}+c_{2} \cdot V B_{\mathrm{SE}}+c_{3} \quad(\mathrm{~mm}) \\
\Delta D_{D} & =b_{1} \cdot L_{C}^{b_{2}} \cdot\left(b_{3} \cdot t_{N}^{2}+b_{4} \cdot t_{N}+b_{5}\right)+b_{6} \quad(\mathrm{~mm})
\end{aligned}
$$

During the evaluation process of all models, elimination of unimportant or low import estimators was carried out by 
use of a coefficient of relative importance $C_{R I}$, defined by Eq. (5), by assumption $C_{R I}>0.1$.

$$
C_{R I}=\left(S_{K}-S_{K O k}\right) \cdot S_{K}^{-1} \cdot 100(\%)
$$

In Eq. (5) the new terms are:

$S_{K O k}-$ summation of square of residuals, by estimator $a_{k}=0$,

$a_{k}-\quad$ estimator of number $k$ in the statistical model evaluated.

The summation of residuals square $S_{K}$, standard deviation $S_{D}$ the square of correlation coefficient of the predicted, and observed values $R^{2}$ were used for characterization of approximation quality. Calculations were performed at Poznań Supercomputing and Networking Center (PCSS) on an SGI Altix 3700 machine, using an optimization program based on a least squares method combined with gradient and Monte Carlo methods (Porankiewicz 1988). This program was modified several times in order to increase calculations efficiency.

\section{RESULTS AND DISCUSSION}

The following estimators for Eq. (2), describing the dependence $V B_{S E}=f\left(L_{C}, t_{N}\right)$ were evaluated: $a_{1}=-1.158 \cdot 10^{-5}$, $a_{2}=0.52617, a_{3}=0.05005, a_{4}=1.77155, a_{5}=-872.54993$, $a_{6}=-0.02225$.

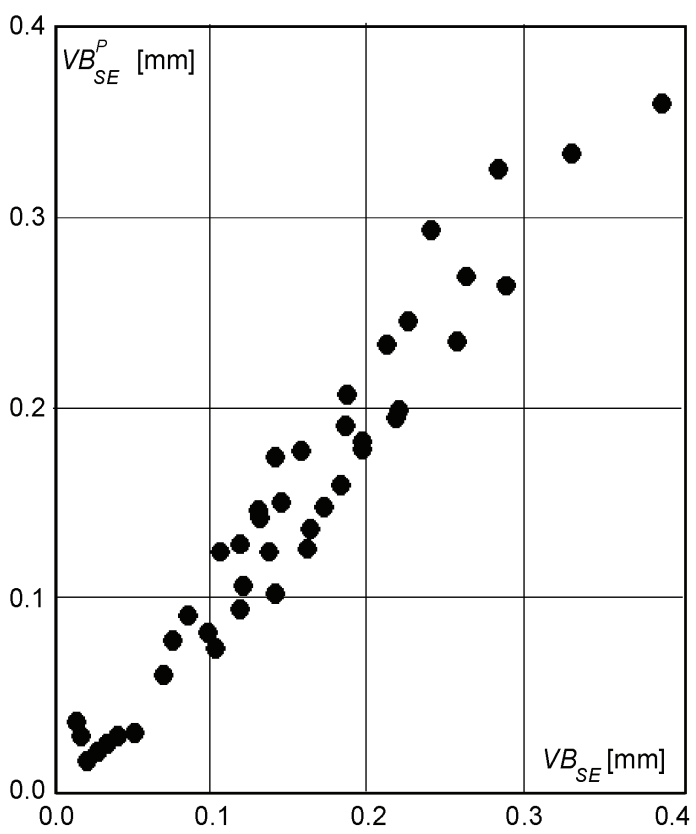

Fig. 4. The plot of observed drill bit side edge recessions $V B_{S E}$ against predicted $V B^{P}{ }_{S E}$ value, according to Eq. (2)
The approximation quality of the fit of Eq. (2) can be characterized by the quantifiers: $S_{K}=0.019, R=0.97$; $R^{2}=0.94 ; S_{D}=0.022 \mathrm{~mm}$, and was also illustrated in Fig. 4 .

The coefficients of relative importance $C_{R I}$ for estimators of Eq. (2) were as follows: $C_{R I 1}=8374, C_{R I 2}=8024$, $C_{R I 3}=874, C_{R I 4}=231, C_{R I 5}=16301$ and $C_{R I 6}=110$. The plots shown in Fig. 4 suggested the presence of not recognized variation, in range of $V B_{S E}<0.05 . .0 .3>\mathrm{mm}$, with the largest value of about $0.08 \mathrm{~mm}$. This variation could be generated by HTTR (Porankiewicz 2003) as well as the content and size of mineral contamination, which were not evaluated in the analyzed experiment. Figure 5 shows that the drill bit side edge recession $V B_{S E}$ strongly depended upon the thickness of the nitrided coating layer $t_{N}$ $(\mu \mathrm{m})$. With enlargement of the $t_{N}$ the side edge recessions $V B_{S E}$ significantly decreased.

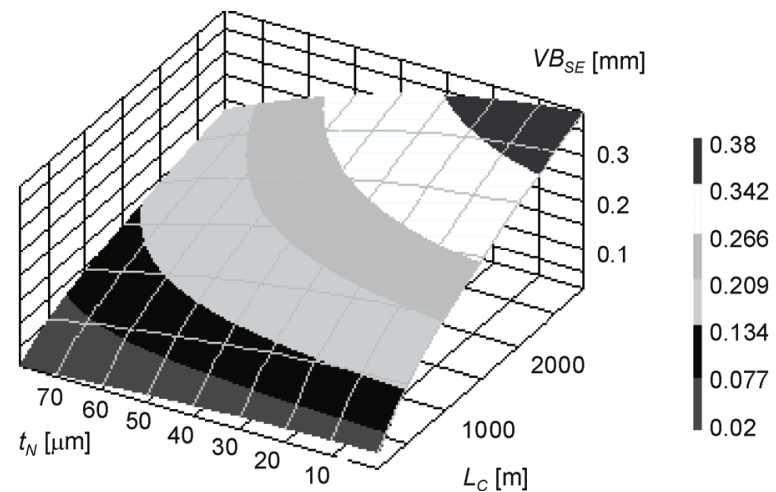

Fig. 5. The plot of relation between the drill bit site edge recession $V B_{S E}$ and the cutting path $L_{C}$ and the thickness of the nitrided coating layer $t_{N}$, according to Eq. (2)

The largest nitrided coating of $78 \mu \mathrm{m}$ caused as much as 2.2 times increase of the side edge recession $V B_{S E}$, after the longest cutting path $L_{C}$ of $2884 \mathrm{~m}$. The side edge nitrided coating of $78 \mu \mathrm{m}$ was worn out after cutting a path of about $L_{C}=724 \mathrm{~m}$. After the shortest cutting path $L_{C}$ of $103 \mathrm{~m}$, the nitrided coating of $78 \mu \mathrm{m}$ caused a 3.8 times increase of the side edge recessions $V B_{S E}$. The drop down of the quotient of the side edge recession increase, from 3.8 to 2.2 , (for the shortest and the longest cutting path $L_{C}$ ) suggests that with cutting path $L_{C}$ increase, due to larger temperature of the top of the side edge, more wearing mechanisms were involved. It seems that a thicker nitrided layer, possible by a slightly larger side edge wedge angle might be useful for increasing the drill bits tool life. Figure 5 also show that the side edge recession $V B_{S E}$ strongly depended upon the cutting path $L_{C}$. An enlargement of the cutting path $L_{C}$ enlarged parabolically, with 
a decreasing rate the side edge recessions $V B_{S E}$. By the largest nitrided coating of $78 \mu \mathrm{m}$, the cutting path $L_{C}$ increase from $103 \mathrm{~m}$ up to $2884 \mathrm{~m}$ increased as high as 13.9 times the side edge recessions $V B_{S E}$, while only as many as 8.6 times for the thinest nitrided layer coating of $30 \mu \mathrm{m}$. This observation suggests that more wearing mechanisms were involved in side edge wearing, rendering the situation more complex, in case of the thickest nitrided layer in comparison to the thinnest one. The quotients 2.2, 3.8 and 13.9 were calculated, in reference to the initial value of the drill bit side edge recession $V B_{S E}$ evaluated for the cutting path $L_{C}=0 \mathrm{~m}$.

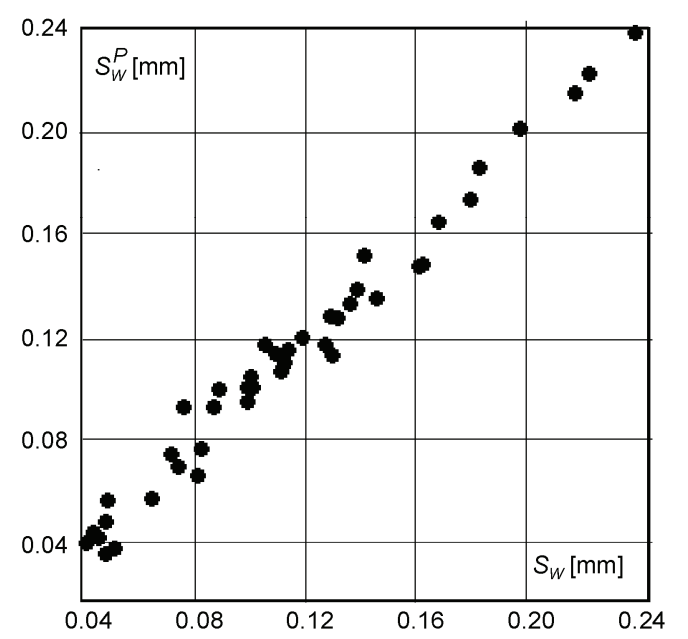

Fig. 6. The plot of observed hole edge swelling $S_{W}$ against the predicted $S^{P}$ value, according to Eq. (3)

The following estimators for Eq. (3), describing dependence $S_{W}=f\left(V B_{S E}\right)$ were evaluated: $c_{1}=0.191927$, $c_{2}=0.49399, c_{3}=0.03348$. The approximation quality of the fit of the Eq. (3) can be characterized by quantifiers: $S_{K}=0.002, R=0.99, R^{2}=0.99, S_{D}=0.008 \mathrm{~mm}$, and was also illustrated in Fig. 6. The coefficients of relative importance $C_{R I}$ for estimators of Eq. (3) were as follows: $C_{R I I}=136, C_{R I 2}=14080, C_{R I 3}=2091$. Figure 6 shows larger dispersion of the results in the first half of the plot as large as $0.03 \mathrm{~mm}$.

Although the relation $S_{W}=f\left(V B_{S E}\right)$ shown in Fig. 7 appeared to be linear, a better fit was obtained when using a parabolic approximation function. The edge swelling $S_{W}$ is a sensitive and most important technological criterion of visible hole edge in a coated particle board drilling operation. The edge swelling $S_{W}$ resulted from melting PVC coating by the drill bit side edge action under increased temperature in a cutting contact region, as well as swelling the outer layer of the particle board core adjacent to holes edge. Both effects are strongly dependent upon the drill bit side edge dullness, as it was shown in Fig. 7. However, what is also worth mentioning is the critical role of tear-off strength of the thin skin of a particle board on the total hole edge swelling (Porankiewicz 2003). Assuming that there is an acceptable level of the swelling $S_{W} \leq 0.1 \mathrm{~mm}$, the corresponding drill bit side edge wear $V B_{S E}$, according to Eq. (2) was as high as $V B_{S E}=0.129 \mathrm{~mm}$, and, for the thickest nitrided layer of $t_{N}=78 \mu \mathrm{m}$, this side edge wear $V B_{S E}$ occurred after the cutting path of $L_{C}=1644 \mathrm{~m}$, while by drilling holes with the use of uncoated drill bits, the same side edge wear $V B_{S E}$ resulted after cutting path of only $L_{C}=429 \mathrm{~m}$. According to this technological criterion, the SW12C steel drill bit life increase due to controlled gas nitriding coating was as high as 3.8 .

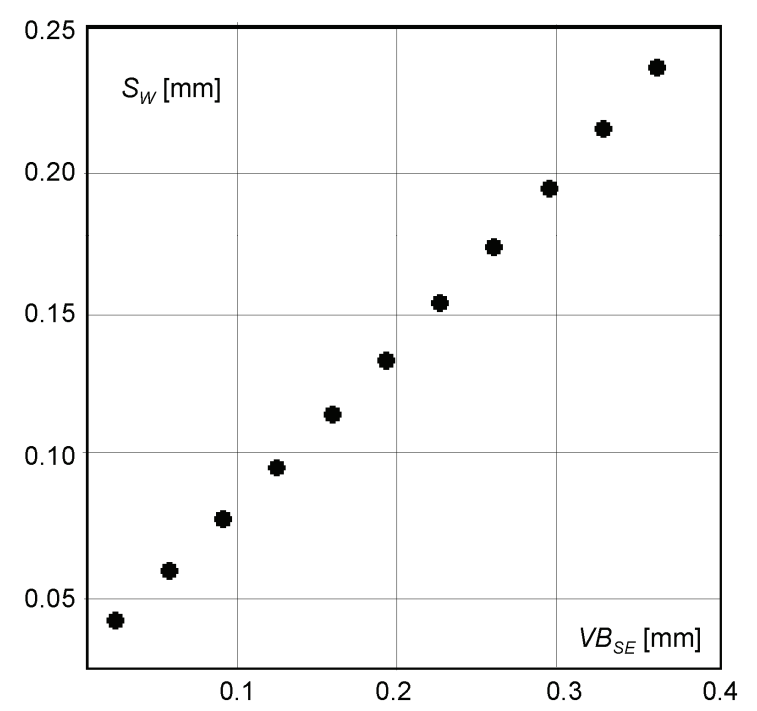

Fig. 7. The plot of impact of drill bit site edge recession $V B_{S E}$ on the hole edge swelling $S_{W}$, according to Eq. (3)

The following estimators for Eq. (4), describing the dependence $\Delta D_{D}=f\left(L_{C}, t_{N}\right)$ were evaluated: $b_{1}=-1.093 \cdot 10^{-5}$, $b_{2}=0.41913, b_{3}=-0.04456, b_{4}=10.23511, b_{5}=-758.96364$, and $b_{6}=0.001589$. The approximation quality of the fit of Eq. (4) can be characterized by the following quantifiers: $S_{K}=0.0062, R=0.96, R^{2}=0.93, S_{D}=0.013 \mathrm{~mm}$, and was also illustrated in Fig. 8. The coefficients of relative importance $C_{R I}$ for estimators of Eq. (4) were as follows: $C_{R I 1}=4935, C_{R I 2}=4478, C_{R I 3}=937, C_{R I 4}=10438, C_{R I 5}=$ $=16785$, and $C_{R I 6}=2$.

The plot shown in Fig. 8, similarly to Fig. 4, suggested presence of not recognized variation, in range of $\Delta D_{D}<0.09 \ldots 0.12>\mathrm{mm}$. 


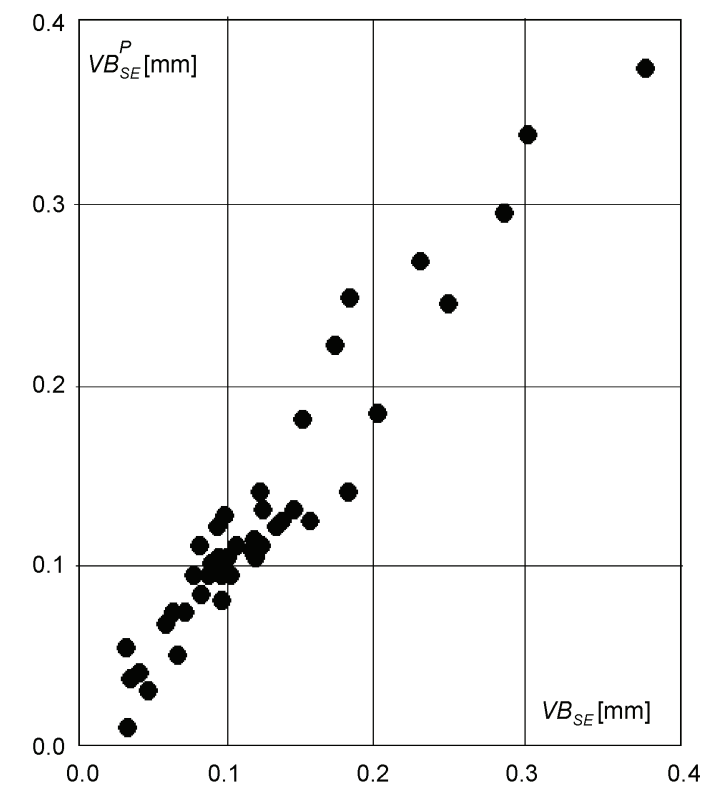

Fig. 8. The plot of observed recession of drill bit diameter $\Delta D_{D}$ against predicted values $\Delta D^{P}$, according to Eq. (4)

The largest nitrided coating of $78 \mu \mathrm{m}$ caused as much as 3.2 times decrease of the drill bit diameter recession $\Delta D_{D}$, resulting in $87 \%$ use out of its initial thickness after the longest cutting path $L_{C}$ of $2884 \mathrm{~m}$. After the shortest cutting path $L_{C}$ of $103 \mathrm{~m}$, the nitrided coating of $78 \mu \mathrm{m}$ caused a 3.1 times decrease of the drill bit diameter recession $\Delta D_{D}$. Figure 9 also shows that the drill bit diameter recession $\Delta D_{D}$ strongly depended upon total cutting path $L_{C}$. Enlargement of cutting path $L_{C}$ parabolically, with a decreasing rate enlarged drill bit diameter recession $\Delta D_{D}$. By the thickest nitrided coating of $78 \mu \mathrm{m}$ the cutting path $L_{C}$ enlargement from $103 \mathrm{~m}$ up to $2884 \mathrm{~m}$, increased as much as 3.8 times the drill bit diameter recession $\Delta D_{D}$. By the thinnest nitrided coating of $30 \mu \mathrm{m}$ the cutting path $L_{C}$ increase from $103 \mathrm{~m}$ up to 2884 $\mathrm{m}$ increased, as much as 3.9 times the drill bit diameter

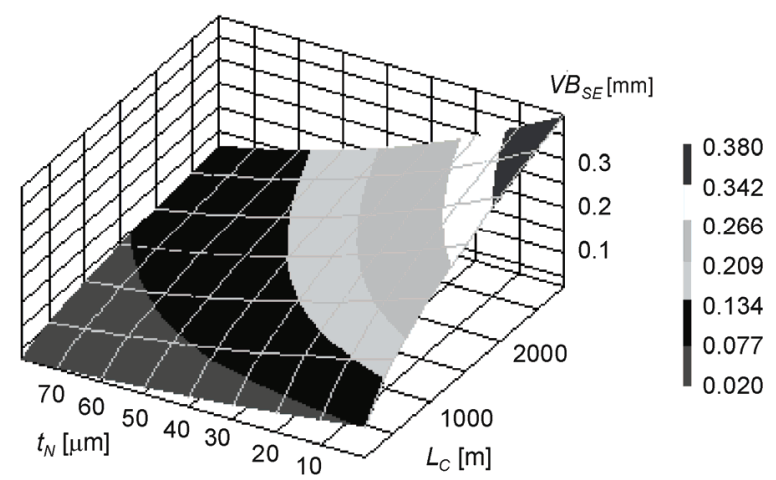

Fig. 9. The plot of relation between site edge recession $\Delta D_{D}$ and cutting path $L_{C}$ and the thickness of nitrided coating layer $t_{N}$, according to Eq. (2) recession $\Delta D_{D}$. This observation suggests that the drill bit diameter recession wearing mechanism remained similar for thin and thick drill bit side surface nitrided coatings on the cutting path examined.

\section{CONCLUSIONS}

1. When drilling the wide surface of the PVC-coated particle board, the drill bit side edge recession $V B_{S E}$ strongly depends upon the thickness of the nitrided coating layer $t_{N}$. With enlargement of the $t_{N}$ the side edge recessions $V B_{S E}$ significantly decreased, as much as 2.2 times for the thickest nitrided coating $t_{N}$ of $78 \mu \mathrm{m}$ and the longest cutting path $L_{C}$ of $2884 \mathrm{~m}$.

2. After the shortest cutting path $L_{C}$ of $103 \mathrm{~m}$, an increase of the nitrided coating up to $78 \mu \mathrm{m}$, the drill bit side edge recessions $V B_{S E}$ decrease was as high as 3.76 times.

3. The drill bit side edge recession $V B_{S E}$ strongly depends upon the cutting path $L_{C}$. An increase of the cutting path $L_{C}$ parabolically enlarge, with a decreasing rate, the drill bit side edge recession $V B_{S E}$.

4. The drill bit side edge recession $V B_{S E}$ wearing mechanism became more complex for thick drill bit side surface nitrided coating on the cutting path $L_{C}$ from $103 \mathrm{~m}$ to $2884 \mathrm{~m}$.

5. The drill bit diameter recession $\Delta D_{D}$ strongly depends upon the thickness of nitrided layer $t_{N}$. An enlargement of the thickness of nitrided layer $t_{N}$ non-linearly decreased the drill bit diameter recession $\Delta D_{D}$, as much as 3.2 times for the thickest nitrided coating of $78 \mu \mathrm{m}$ and the cutting path $L_{C}$ as large as 2884 .

6. The hole edge swelling $S_{W}$ after drilling is strongly dependent upon the drill bit side edge dullness $V B_{S E}$.

7. Using the hole edge swelling $S_{W}$ as a technological criterion, the SW12C steel drill bit life increase due to controlled gas nitriding coating was as high as 3.8.

8. The drill bit diameter recession $\Delta D_{D}$ strongly depends upon the total cutting path $L_{C}$. Enlargement of the total cutting path $L_{C}$ parabolically with decreasing rate enlarged the drill bit diameter recession $\Delta D_{D}$ as much as 3.2 times for the thickest nitrided coating of $78 \mu \mathrm{m}$ and the cutting path $L_{C}$ increase from $103 \mathrm{~m}$ to $2884 \mathrm{~m}$.

9. After the cutting path $L_{C}$ increase from $103 \mathrm{~m}$ to $2884 \mathrm{~m}$, for the thinnest nitrided coating of $30 \mu \mathrm{m}$, the drill bit diameter recession $\Delta D_{D}$ decrease was as high as 3.9 times.

10. The drill bit diameter recession wearing mechanism remained similar for the thin and thick drill bit side 
surface nitrided coatings on the cutting path $L_{C}$ from $103 \mathrm{~m}$ to $2884 \mathrm{~m}$.

\section{Acknowledgements}

The authors are grateful for the support of the Poznan Supercomputing and Networking Center (PCSS) calculation grant.

\section{References}

[1] P. Beer, S. Miklaszewski, A. Sokołowska, Tribological Properties of Wood. Proc. of 10 Jubilee International Summer School, Mielno'98, Koszalin, Poland, 141-160 (1998).
[2] L. Chekour, C. Nouveau, C. Chala, M.-A. Djouadi, Duplex treatment of $32 \mathrm{CrMoV} 13$ steel by ionic nitriding and triode sputtering: application to wood machining. Wear 255, 1438-1443 (2003).

[3] B. Porankiewicz, Tępienie się ostrzy i jakość przedmiotu obrabianego $w$ skrawaniu plyt wiórowych. Printing House, Agricultural University of Poznań, 341 (2003).

[4] A. Sokołowska, P. Beer, J. Rudnicki, Niskotemperaturowe azotowanie jarzeniowe noży do produkcji tuszczki. Problemy Eksploatacji, 2, 359-366 (2000).

[5] W. Szymański, Badania wplywu grubości warstwy azotowanej na trwatość wiertel ze stali szybkotnacej przy wierceniu plyt wiórowych. Akademia Rolnicza w Poznaniu, Instytut Podstaw Techniki, Master thesis (1977)

[6] W. Szymański, B. Porankiewicz, L. Małdziński, Wpływ azotowania gazowego na trwatość wiertet do drewna. Roczniki Akademii Rolniczej w Poznaniu CXXV: 71-79 (1980).
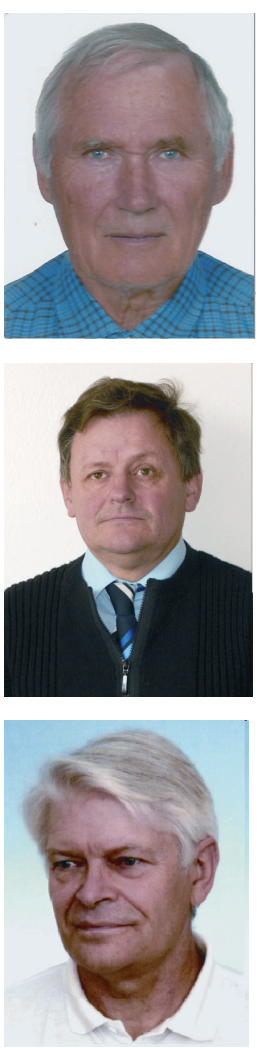

Bolestaw Porankiewicz, retired and habilitated in 2004 year at the Agricultural University of Poznań, Faculty of Wood Technology, where he also received his Doctor of Technical Science and the MSc degrees in years 1973 and 1968 respectively. In the years 2008-2011 he was employed as the contract professor at the University of Zielona Góra, Faculty of Mechanical Engineering. Research interest: wood cutting forces, cutting accuracy, wearing of wood cutting tools, construction and exploitation of wood cutting tools and woodworking machinery.

Leszek MaŁdziński, Professor at Poznań University of Technology. He is also the project leader and scientific adviser at Secowarwick Poland. He was previously employed as a scientist at the Delft Technical University, Netherlands. He was scientific adviser of Nitrem Metal Inc. at Montreal, Canada and Colmeng at Milan, Italy. He received his scientific degrees $\mathrm{MSc}, \mathrm{PhD}$ and habilitation at the Poznań University of Technology. His area of interest is thermodynamics and kinetics of steel gas nitriding. The result of the work in this area are 50 publications. He developed a new economical and ecological method called ZeroFlow, which is characterized by several times less wear of technical gases (ammonia, nitrogen) and post-process gases emission into the atmosphere when compared with current methods. ZeroFlow method has already been implemented in several industrial plants in Poland, England, the FRG, Pakistan, India and Singapore. At present ZeroFlow runs in the Volvo plant in Sweden.

Grzegorz Wieloch, PhD, DSci, is Assistant Professor in Department of Woodworking Machinery and Basic Construction, Faculty of Wood Technology, University of Life Sciences in Poznań. In the 70s he worked at the Institute of Wood Technology. His professional and research interests are connected with wood and wood products machining especially machines and tools for above mentioned materials. The research conducted was concentrated on different aspects starting with tool construction, its applications and increase of their durability. The most important works concern surface quality formed via chip and chipless machining (for example via burnishing). He also researched chip and dust creation during cutting and their dedusting. 